\title{
Correction to: Burning Numbers of $t$-unicyclic Graphs
}

Ruiting Zhang ${ }^{1} \cdot$ Yingying $\mathrm{Yu}^{1} \cdot$ Huiqing Liu ${ }^{1}$

Published online: 10 January 2022

๑ Malaysian Mathematical Sciences Society and Penerbit Universiti Sains Malaysia 2022

\section{Correction to: Bull. Malays. Math. Sci. Soc. (2022) 45:417-430 https://doi.org/10.1007/s40840-021-01194-9}

The Funding information section was missing from this article and should have read 'Partially supported by NSFC under Grant Number 11971158'.

The original article has been corrected.

Publisher's Note Springer Nature remains neutral with regard to jurisdictional claims in published maps and institutional affiliations.

The original article can be found online at https://doi.org/10.1007/s40840-021-01194-9.

$\bowtie \quad$ Huiqing Liu

hq1_2008@163.com

1 Hubei Key Laboratory of Applied Mathematics, Faculty of Mathematics and Statistics, Hubei University, Wuhan 430062, People's Republic of China 